\title{
Anatomical and radiographic appearance of the capuchin monkey thoracic cavity (Cebus apella) ${ }^{1}$
}

INDEX TERMS: Capuchin monkey, brown capuchin, Cebus apella, radiography, wild animals, Amazon.

RESUMO.- [Aparência anatômica e radiográfica da cavidade torácica do macaco-prego (Cebus apella).] 0 macaco-prego é muito comum tanto no norte, quanto no sul da

\footnotetext{
${ }^{1}$ Received on February 28, 2012.

Accepted for publication on September 6, 2012.

${ }^{2}$ Departamento de Morfisiologia Veterinária, Curso de Medicina Veterinária, Universidade Federal do Piauí (UFPI), Campus Universitário Ministro Petrônio Portella, Bairro Ininga, Teresina, PI 64049-550, Brazil.

* Corresponding author: flavioribeiro@ufpi.edu.br

${ }^{3}$ Programa de Pós-Graduação em Epidemiologia Experimental Aplicado às Zoonoses, Faculdade de Medicina Veterinária e Zootecnia (FMVZ), Universidade de São Paulo (USP), Av. Prof. Dr. Orlando Marques de Paiva 87, São Paulo, SP 05508-270, Brazil.

${ }^{4}$ Veterinário Autônomo, Av. Dom Pedro II s/n, Belo Horizonte, MG 30750-000, Brazil.

${ }^{5}$ Programa de Pós-Graduação em Ciência Animal, UFPI, Teresina, PI.

${ }^{6}$ Programa de Pós-Graduação em Ciências Veterinárias, Universidade Estadual do Maranhão (UEMA), Campus Paulo VI s/n, São Cristovão, São Luís, MA 65055-900, Brazil.

${ }^{7}$ Departamento de Ciências Básicas, Faculdade de Zootecnia e Engenharia de Alimentos, USP, Av. Duque de Caxias Norte 225, ZAB, Pirassununga, SP 13635-900, Brazil.

${ }^{8}$ Departamento das Clínicas, Curso de Medicina Veterinária, UEMA, Campus Paulo VI s/n, São Luís, MA.
}

Amazônia Legal e no cerrado brasileiro. Dez macacos-prego clinicamente saudáveis foram submetidos a um estudo anatômico e radiográfico de suas cavidades torácicas. A avaliação radiográfica permitiu a descrição de valores biométricos associados à silhueta cardíaca e estruturas torácicas. A aplicação do método de VHS (vertebral heart size) demonstrou correlação positiva $(\mathrm{P}<0,05)$ com a profundidade da cavidade torácica, assim como entre o comprimento do corpo de vértebras T3, T4, T5 e T6 e do comprimento e largura cardíaca. Os campos pulmonares apresentaram padrão intersticial difuso, mais visível nos lobos pulmonares caudais e um padrão brônquial em lobo pulmonar médio e cranial. 0 exame radiográfico permitiu inferências preliminares a serem realizadas no âmbito da sintopia das estruturas torácicas e de modificação dos padrões pulmonares e anatomia cardíaca para o macaco-prego.

TERMOS DE INDEXAÇÃO: Macaco-prego, Cebus apella, radiografia, animal silvestre, Amazônia.

\section{INTRODUCTION}

The capuchin monkey, Cebus apella, is widespread both north and south of the Legal Amazon and in the Brazilian 
cerrado, places where human intervention is intense and continual. Capuchin monkey is the generic designation of the oldest Cebus apella species (Freese \& Oppenheimer 1981). The species have a wide variation in their coat color, ranging from light yellow to dark brown, the top of the head, legs and tail are always a darker shade and the tail is prehensile. The progressive destruction of green areas, the natural habitat of these animals, has led them to migrate to other regions, making them more susceptible to poaching (Mittermeir \& Coimbra-Filho 1977).

The need for wild species preservation brings with it the requirement for more clinical and anatomical knowledge of these animals. Breeding in captivity is already a reality (Csatadi, Leus \& Pereboom 2008); but there has been little discussion on the use of minimally invasive investigative techniques for primate thoracic radiography focusing on the cardiac silhouette (Medd 1971, Silverman 1975, Silverman \& Morgan 1980). Other related studies were conducted in western primates concerning the radiographic anatomy of the thoracic cavity (Wagner \& Kirberger 2005, Schillaci et al. 2007, Schillaci 2008) and some studies evaluated the $\mathrm{Ce}$ bus apella reproductive tract (Alves et al. 2007, Domingues et al. 2007). However, there is no reference to the capuchin monkey and it is worth mentioning that the Cebus apella anatomy is not as well known as that of other monkeys, perhaps due to its restriction to the South American Continent.

Increased demand for information regarding the Cebus apella anatomy leads us to verify the possibility of radiographic characterization of the structures present in the thoracic cavity of this species and the potential application of VHS method to evaluate increases in cardiac volume, providing knowledge on its limits and relation of syntopy with adjacent organs, thus building the necessary tools for the medical and surgical treatment of $C$. Apella.

\section{MATERIALS AND METHODS}

\section{Animals}

Ten adult, clinically healthy capuchin monkeys (Cebus paella) were used from the Centro de Triagem de Animais Silvestres (Cetas) (Wild Animal Screening Center) located in São Luis, Maranhão state, Brazil. The animals were grouped according to their arrival at CETAS, so they were divided into two groups, consisting of six males and four females, with age ranging from 4 to $8 \mathrm{~cm}$. Were considered suitable for the experiment animals with normal blood hematological profile (Wirz, Truppa \& Riviello 2008), and after the cardiorespiratory examination showed pink colored mucous, clear breath sounds and normal cardiac rhythm (without atrial fibrillation, ventricular tachycardia, blocks or sinusal pause).

Their age was estimated based on the observed pattern of dental eruption. The experimental project was approved by the Brazilian Institute of Environment and Renewable Natural Resources (BAMA, protocol no 02012.003909/2006).

\footnotetext{
Anesthetic procedure

The animals were subjected to chemical restraint using acepromazine (ACEPRAN, Campinas, SP) at 1\%, a phenothiazine with central action, in dosages of $0.1 \mathrm{mg} / \mathrm{kg}$, intramuscularly, waiting for 20 minutes before starting to handle the animals. The anesthetic protocol was then followed using ketamine hydrochloride at
}

5\% (VETANARCOL, São Paulo, SP) at a dose of $11 \mathrm{mg} / \mathrm{kg}$ combined with diazepam (VALIUM, São Paulo, SP), at a dose of $0.25 \mathrm{mg} / \mathrm{kg}$, intramuscularly and the radiographic examination was made after 15 minutes. The combination used in this anesthetic protocol lasted an average of 45 minutes in all evaluations; therefore, there was no need for successive drug re-administration.

\section{Radiographic exam}

The animals were positioned supine and lateral to obtain radiographic images of the ventrodorsal and lateral view projection of the thoracic region, respectively. In both positions, the animals had their forelimbs pulled cranially to prevent the biceps muscles from overlapping the lung fields. For this, a portable x-ray machine 8016 HF Portable X-ray Unit was used, calibrated with a focus-film distance of $80 \mathrm{~cm}$ and exposure techniques of $40 \mathrm{kVp}$ and 0.2 mAs, a $24 \times 30 \mathrm{~cm}$ metal chassis, with CRONEX HI plus intensifier screens and RPX-OMAT films. The films were developed and fixed in a RPX-OMAT automatic film processor. The radiographs were then digitized and documented for further evaluation.

\section{Image evaluation}

First, the radiographic images were analyzed for observable pulmonary pattern for the species for a Veterinary Radiologist Diagnostic Imaging (DVM, PhD). Then the morphometric evaluation of the thoracic cavity was carried out.

Angle of cardiac inclination. The angle of cardiac inclination was evaluated using as reference the angle formed between the right cardiac border and the sternum, by laterolateral projections (Fig.1a).

Cardiac diameter and length. The cardiac diameter was measured in latero-lateral radiographs, using as reference the greater diameter of the cardiac silhouette. The heart length was checked by measuring the distance between the apex of the heart and the carina region located dorsally to the base of the heart (Fig.1a).

Tracheal inclination. The tracheal inclination was measured using radiographic images in laterolateral projection, using as reference the angle formed by the ventral surface of the bodies of thoracic vertebrae and the trachea (Fig.1a).

Thoracic depth. The thoracic depth was measured using radiographs in laterolateral projection, based on the distance between the ventral surface of the vertebral body and the xiphoid cartilage at the level of caudal margin of the sixth pair of ribs (Fig.1a).

VHS. The VHS was measured according to the protocol established by Buchanan and Bücheler (1995), where the sum of the cardiac length and cardiac width at its largest diameter is compared with the vertebral bodies from T4 (Fig.1a).

Costophrenic angles. The costophrenic angles were measured from the right and left sides; the animal was placed in dorsal recumbency, through ventrodorsal projections of the thoracic cavity (Fig. 1b).

Distance between the chest wall and the heart. The distance between the chest wall and the heart was determined in ventrodorsal projection radiographs, measuring the distance between the right and left chest wall in relation to the cardiac silhouette (Fig.1b).

Thoracic cavity length. The thoracic cavity length was measured using ventrodorsal projection radiographs, based on the distance between the thoracic inlet and the most cranial portion of the cupola of the diaphragm (Fig.1b).

\section{Statistical analysis}

Data were presented as means and standard deviations. The Pearson's Correlation Coefficient $(r)$ was calculated to demonstrate the interaction between the set of variables analyzed with significance level of $5 \%(\mathrm{p}<0.05)$. 


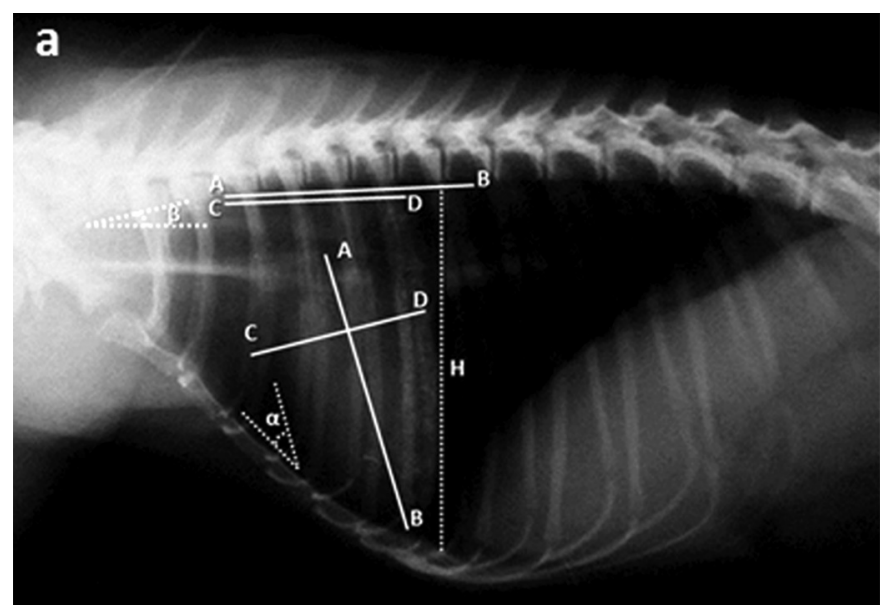

Fig.1. Inspiratory chest radiograph of an adult capuchin monkey. (a) Left-to-right lateral recumbent radiograph to measure the biometric values of the following thoracic structures: $\alpha$ - cardiac inclination angle; $\beta=$ Tracheal Inclination; $H=$ Thoracic depth. Note that the VHS is measured by the sum of the cardiac length "AB" and cardiac width "CD" at its largest diameter and its comparison with the vertebral bodies from T4. (b) Ventrodorsal radiograph to measure the Costophrenic angles ( $\sigma$ and $\sigma^{\prime}$ ); Distance between the chest wall and the heart (EF, $\left.\mathrm{E}^{\prime} \mathrm{F}^{\prime}\right)$ and thoracic cavity length (GI).

\section{RESULTS}

The animals analyzed showed $6.1 \pm 1.13$ years (SD) and weight with averaged $3: 58 \pm 0.19 \mathrm{~kg}(\mathrm{SD})$. The body condition score was similar and no great variation in size among males and females, with males slightly larger, but still sub-adults for the average age of the animal studies.

\section{Thoracic cavity and heart biometry}

Radiographic evaluation of the capuchin monkey chest, from lateral and ventrodorsal views, showed cardiac biometric indices for to the thoracic cavity as follows (mean and standard deviation): mean cardiac inclination of $51.1 \pm 1.73^{\circ}$; cardiac diameter $3.2 \pm 0.35 \mathrm{~cm}$ and cardiac length $4.5 \pm 0.43 \mathrm{~cm}$. The measurement in laterolateral radiographs for the tracheal inclination showed a mean value of $17 \pm 2.58^{\circ}$. The right and left costophrenic angles were evaluated in ventrodorsal projection and measured, respectively, $33.8 \pm 1.75^{\circ}$ and $31.1 \pm 1.10^{\circ}$. Under the same projection the measurements for the distances of the cardiac silhouette, in relation to the right and left walls of the thoracic cavity, were, respectively, $1.52 \pm 0.26 \mathrm{~cm}$ and $0.84 \pm 0.14 \mathrm{~cm}$. Measurements for the thoracic length and depth were $6.27 \pm 0.78 \mathrm{~cm}$ and $5.83 \pm 0.41 \mathrm{~cm}$, respectively. The mean value of the vertebral heart size (VHS) measured for the species was $9.85 \pm 0.63$ (Table 1). The VHS showed significant positive correlation $(\mathrm{P}<0.05)$ with the depth of the thoracic cavity. The mean diameter of the caudal vena cava was $0.76 \pm 0.14 \mathrm{~cm}$.

\section{Vertebral column and thoracic vertebrae biometry}

The morphology of the vertebrae that compose the vertebral column of the capuchin monkey, observed by radiographic examination, allowed us to divide them into: Cer-

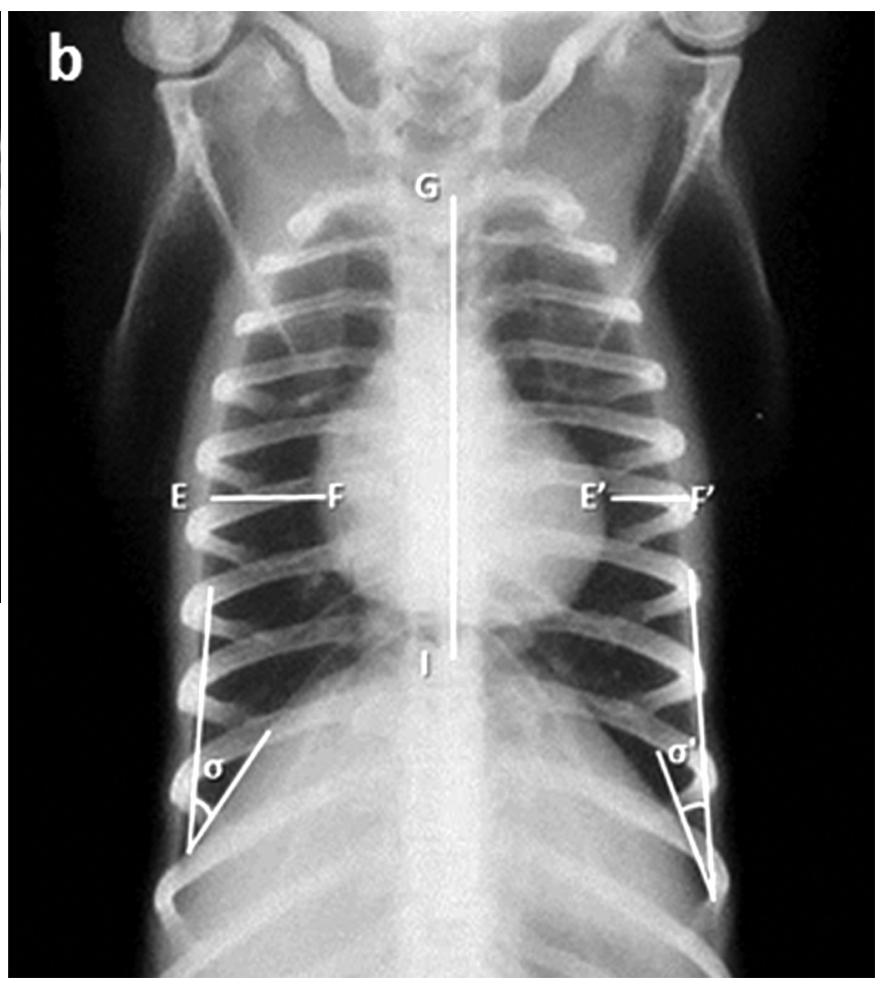

vical (7), Thoracic (12 or 13), Lumbar (6) and Sacral (3 or 4) (Table 2).

The length measured from the cranial surface of $T_{1}$ to the caudal surface of the last thoracic vertebra averaged $10.15 \pm 0.90 \mathrm{~cm}$, ranging from 8.55 to $11.50 \mathrm{~cm}$. The body length of the vertebrae showed a gradual and heterogeneous increase from the first to the last thoracic vertebra, so, while the difference in length between $\mathrm{T}_{1}$ and $\mathrm{T}_{8}$ ranged

Table 1. summarized radiographic measurements of the thorax in 10 adults capuchin monkeys

\begin{tabular}{lccccc}
\hline \multicolumn{1}{c}{ Variables } & $\begin{array}{c}\text { Number of } \\
\text { capuchin } \\
\text { monkeys }\end{array}$ & & & & \multicolumn{2}{c}{$\begin{array}{c}\text { Mini- Maxi- } \\
\text { mum }\end{array}$} & & & mum \\
\hline Cardiac angle (deg) & 10 & 51.1 & 1.73 & 50 & 55 \\
Cardiac diameter (cm) & 10 & 3.2 & 0.35 & 2.7 & 3.9 \\
Cardiac length (cm) & 10 & 4.42 & 0.43 & 3.9 & 5.2 \\
Tracheal angle (deg) & 10 & 17 & 2.58 & 15 & 20 \\
Right costophrenic angle (deg) & 10 & 33.8 & 1.75 & 30 & 35 \\
Left costophrenic angle (deg) & 10 & 31.1 & 1.10 & 30 & 33 \\
Right chest wall/heart distance (cm) & 10 & 1.54 & 0.26 & 0.6 & 1.0 \\
Left chest wall/heart distance (cm) & 10 & 0.84 & 0.14 & 1.1 & 1.9 \\
Thoracic deepth (cm) & 10 & 5.83 & 0.41 & 5.2 & 6.4 \\
Thoracic length (cm) & 10 & 6.27 & 0.78 & 4.9 & 7.7 \\
VHS & 10 & 9.12 & 0.63 & 9.3 & 11
\end{tabular}

Table 2. Summarized radiographic findings of the skeletal system of 10 adults capuchin monkeys

\begin{tabular}{lccccc}
\hline \multicolumn{1}{c}{ Variables } & $\begin{array}{c}\text { Number of } \\
\text { capuchin } \\
\text { monkeys }\end{array}$ & Mean & SD $( \pm)$ & \multicolumn{2}{c}{ Range } \\
\cline { 4 - 6 } & & & Minimum & Maximum \\
Cervical vertebrae & 10 & 7 & 0.00 & 7 & 7 \\
Thoracic vertebrae & 10 & 12.57 & 0.53 & 12 & 13 \\
Lumbar vertebrae & 10 & 6 & 0.00 & 6 & 6 \\
Sacral vertebrae & 10 & 3.50 & 0.52 & 3 & 4 \\
Sternebrae & 10 & 6 & 0.00 & 6 & 6
\end{tabular}



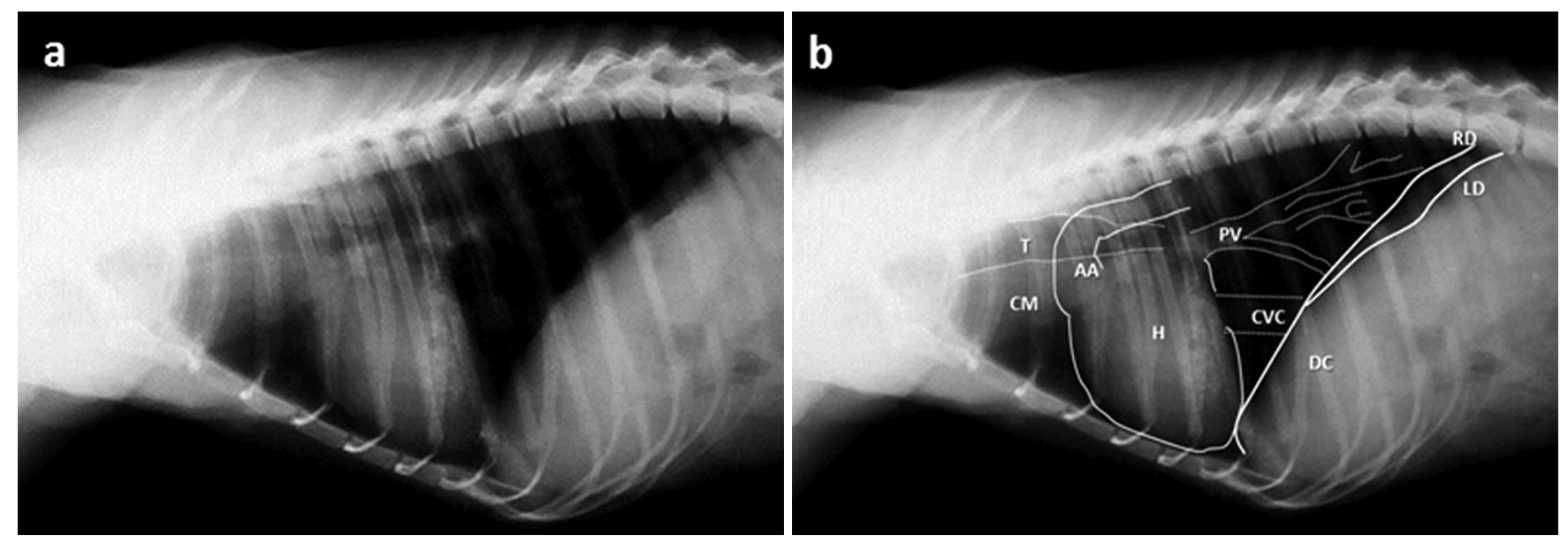

Fig.2. Inspiratory chest radiograph of an adult capuchin monkey. (a) Left-to-right lateral recumbent radiograph to evaluate the radiographic density of structures present in the thoracic cavity. Note the lung pattern varied from diffuse interstitial pulmonary (the caudal lung lobes) to a bronchial pattern sometimes seen in cranial and middle lung lobes. Pulmonary vessels showed divergence from their origin at the cardiac base toward the chest wall. (b) Schematic representation identifying anatomical structures seen in figure "a": $\mathrm{H}=$ cardiac silhouette, $\mathrm{AA}=$ Aorta; $\mathrm{CM}=$ Cranial Mediastinum; $\mathrm{CVC}=$ Caudal vena cava; $\mathrm{T}=$ Trachea, $\mathrm{PV}=\mathrm{Pulmonary}$ vessels; $\mathrm{DC}=$ Diaphragmatic cupola; $\mathrm{RD}=$ Right diaphragmatic crus; $\mathrm{LD}=$ Left diaphragmatic crus.

from 0.10 to $0.20 \mathrm{~cm}$, the difference of $\mathrm{T}_{9}$ to the last thoracic vertebra $\left(\mathrm{T}_{12}\right.$ or $\mathrm{T}_{13}$ ) ranged from 0.15 to $0.30 \mathrm{~cm}$. The average length of the vertebral body of $\mathrm{T} 1$ was $0.65 \pm 0.05 \mathrm{~cm}$, while that of the last vertebra $\left(\mathrm{T}_{12}\right.$ or $\left.\mathrm{T}_{13}\right)$ was $1.11 \pm 0.08 \mathrm{~cm}$.

The vertebral body length of $\mathrm{T}_{3}, \mathrm{~T}_{4}, \mathrm{~T}_{5}$ and $\mathrm{T}_{6}$ had positive correlations $(\mathrm{P}<0.05)$ with the cardiac length and width. Significant correlations $(\mathrm{P}<0.05)$ were also found between the measurement of the total length of the thoracic vertebrae (from the cranial surface of $\mathrm{T}_{1}$ to the caudal surface of the last thoracic vertebra) and measurements of the cardiac length and width; thoracic length and thoracic depth.
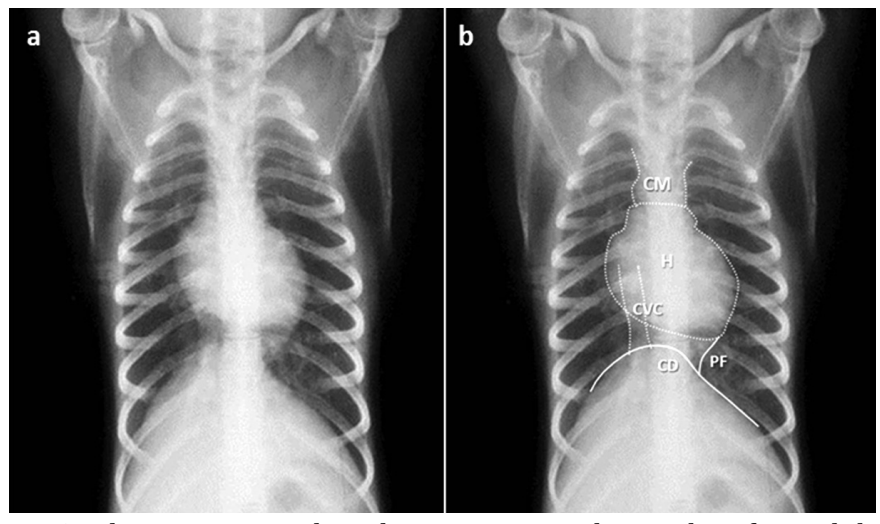

Fig.3. Thoracic ventrodorsal inspiratory radiographs of an adult capuchin monkey. (a) The lung vessels in this projection also showed divergence from the pulmonary hilum towards the chest wall. The aorta was obscured by the cardiac silhouette. The Caudal vena cava is visualized running caudally to the middle level of the chest penetrating through the diaphragmatic crus slightly right of the midline. Note the pleural reflection, visualized as a radiolucent line where the accessory and left caudal lung lobes meet, called by some authors, "phrenicopericardial ligament". (b) Schematic representation identifying the anatomical structures seen in the figure "a": $\mathrm{H}=$ Cardiac silhouette; $\mathrm{CVC}=$ Caudal vena cava; $\mathrm{CM}=$ Cranial Mediastinum; $\mathrm{CD}=$ Diaphragmatic cupola; $\mathrm{PF}=$ Pleural reflection .

\section{Radiographic standard of thoracic structures}

The radiographic densities of structures present in the cranial mediastinum could not be clearly observed individually due to the large number of regional vessels which show radiographic density similar to the regional adipose tissue and smooth muscle of the esophagus. The trachea was characterized as a tubular radiolucent structure, limited by radiopaque rings, perceived from the entrance of the thoracic cavity to its bifurcation in the carina region, where it shows a slight declivity at the base of the heart (Fig.2a,b).

In lateral projection, the heart was seen as a water dense structure, shaped like an inverted cone, occupying the middle mediastinum, between the $4^{\circ}$ and $7^{\circ}$ intercostal space (Fig.2a,b).

The aortic arch was seen due to its water density emerging from the base of the heart, directing dorsocaudally to the level of the proximal third of the $3^{\text {rd }}$ rib and ventral to the thoracic vertebral body, running to the aortic hiatus of the diaphragm. The caudal vena cava was also visualized running caudally to the mid-level of the chest to penetrate through the diaphragmatic crus (Fig.2b). In ventrodorsal projection, the aorta overlapped the cardiac silhouette and it could not be distinguished individually. The right cardiac margin was farther from the thoracic wall, when compared to the left one. The caudal vena cava was caudally related to the cardiac silhouette, with a slightly radiopaque standard, that did not change, regardless of the thoracic radiographic standard at inspiration or expiration (Fig.3a,b).

The pleural reflection along the line where the accessory and left caudal lung lobes meet, called by some authors the "phrenicopericardial ligament", was clearly identified between the apex of the heart and the central portion of the diaphragmatic cupola. The caudal vena cava was seen traversing the caudal aspect of the right hemi-thorax, parallel to the body of the thoracic vertebrae (Fig.3b).

During the radiographs at inspiration, pulmonary vessels showed a dichotomized pattern from their origin at the cardiac base toward the chest wall (vascular pattern), 
decreasing in size as they approached the lung periphery and improved better visualization of the pulmonary vessels than expiratory radiographs. Among the animals studied, eight showed a diffuse interstitial pulmonary, more visible in the caudal lung lobes, while two animals presented also bronchial pattern sometimes seen in cranial and middle lung lobes (Fig.2a and 3a).

\section{DISCUSSION}

\section{Thoracic cavity biometry}

The primary function of the skeleton is to support and distribute body weight harmonically, in order to balance the forces generated in basic situations, such as locomotion. The thoracic conformation of the capuchin monkey is presented as a truncated cone, showing some similarity to descriptions made for the human species (Andriacchi et al. 1974, Cyriax \& Cyriax 1993), although the thoracic cage is laterally compressed, that is probably an adaptive mechanism to the type of locomotion observed in these animals (Hunt et al. 1996).

For the animals studied, the vertebral formula proved to be variable, especially for the thoracic and sacral vertebrae, a situation that was also reported for monkeys of the Callithrix jacchus species (Ankel-Simons 2000, Wagner \& Kirberger 2005). Such variations are commonly observed in domestic species (lumbarization or sacralization), and are important contributors to medullar compressions or nerve bundles (Cauda equina syndrome), or even verified as incidental findings during radiographic evaluation (Ramirez \& Thrall 1998, Morgan et al. 2000). This feature was observed in all the animals evaluated (lumbarization: 7/10 and sacralization $3 / 10$ ), but there was no obvious functional impairment, corroborating the descriptions reported for Callithrix jacchus monkeys (Nassar-Montoya et al. 1992).

The biomechanical aspects of the capuchin monkey vertebral column showed a progressive increase in the length of the vertebral body from T1 to T12/13, which was also reported in human beings [Edmondston et al. 1994, Lee et al. 2007, Masharawi et al. 2008). In fact, these authors attributed this characteristic to the increase in regional compressive loads associated with body weight, distributed at $9 \%$ for $\mathrm{T} 1$, increasing to $33 \%$ in $\mathrm{T} 8$, up to a value of $47 \%$ in T12. Such charge transfer was reflected in the increase in bone density verified radiographically in these animals, following a craniocaudal course from T1 to L6 (Edmondston et al. 1997).

The positive correlations among the thoracic cavity length and the lengths of thoracic vertebrae body lengths denote the possibility of using these measurements to quantify cardiac size increases in capuchin monkeys. Similarly, the positive correlation found for the length of vertebrae T3, T4, T5 and T6, and associating it to the cardiac length and width maintains the possibility of using the VHS method to evaluate increases in cardiac volume in this species, as was proposed in studies on the increase in cardiac silhouette of dogs associating it with the normal cardiac conformation (Buchanan \& Bücheler 1995).

Complete descriptions of these anatomical features in wild animals are still scarce, probably due to limited knowledge of the structures that form their thoracic cavity. Recent radiographic descriptions shown cardiac size increase in six of twenty Macaca nigra, characterized only by morphological evidence. These data supporting the need to standardize a technique to evaluate the normal cardiac conformation easily applied to clinical practice (Schillaci et al. 2008).

\section{Radiographic pattern of thoracic structures}

The laterolateral and ventrodorsal projections resulted in images suitable for identification of thoracic structures. Radiographs at inspiration improved better visualization of the pulmonary vessels and vessels of the heart base, as was also observed and reported for the Callithrix jacchus monkey (Wagner \& Kirberger 2005).

Although the capuchin monkey adopts a semi-upright posture in locomotion, the angulation of the heart, trachea and costophrenic angles was similar to that observed in animals that adopt a quadrupedal posture, as reported for canine and feline species (Nickel et al. 1981, Evans \& Christensen 1993).

The mean values obtained for VHS in capuchin monkeys resembled the values observed in dogs (Litster \& Buchanan 2000), since the VHS values were observed of about $9.7 \pm 0.5$. Although there are deviations in these means among dog breeds (Bavegems et al. 2005), the small variation in body weight and the anatomical conformation of the chest for the capuchin monkey, besides the standardization of the technique for a particular species, could result in obtaining valuable data that could support medical and surgical care of these animals.

Radiographically, the cardiac image of the capuchin monkey occupies the middle third of the rib cage, which is also observed in dogs and cats (Nickel et al. 1981, Evans \& Christensen 1993). Corroborating this, the cardiac image was also described in radiographic studies of the cardiac silhouette in monkeys of the Macaca nigra and Macaca tonkeana species (Schillaci et al. 2007, 2008).

The capuchin monkey heart is in close relationship with the diaphragmatic cupola, at this stage, the diaphragm is largely displaced caudally. Radiographs in ventrodorsal projection favored the visualization of the pleural reflection along the line where the accessory and left caudal lung lobes meet (Schillaci et al. 2007). In these animals, the boundaries of diaphragmatic cupola could be distinguished, regardless of the $x$-ray beam angle, the opposite to what occurs with dogs and cats (Alves et al. 2009).

The pulmonary patterns observed in the Cebus apella species revealed mainly a typical vascular pattern, associated with an interstitial pattern, as was also observed often in dogs (Maï et al. 2008, Kealy et al. 2011). The confirmation of these patterns proved to be difficult, especially for the acquisition of exposure factors that could ensure optimal contrast values for defining the characteristics of pulmonary and thoracic structures. However, once these difficulties were also expressed for the identification of lung patterns in other species of primates, such as marmoset, even after the selection of various techniques for radiographic exposure, we suggest that these limitations may be inherent in the morphology of the thoracic structures of the studied species (Wagner \& Kirberger 2005). 


\section{CONCLUSIONS}

Thus, radiography of the Cebus apella thoracic cavity proved to be a viable technique and was easy to perform, enabling both the biometric evaluation of the thoracic cavity and appropriate visualization to the lung fields and heart in this species. The similarity with other mammalians, such as dogs and cats or even man himself, enable us to comparatively make preliminary inferences about the pulmonary and cardiac pattern from the radiological point of view, generating valuable clinical and surgical benefits for the management and conservation of this wild species.

\section{REFERENCES}

Alves F.R., Costa F.B., Arouche M.M.S., Barros A.C.E., Miglino M.A., Vulcano L.C. \& Guerra P.C. 2007. Avaliação ultra-sonográfica do sistema urinário, figado e útero do macaco-prego, Cebus apella. Pesq. Vet. Bras. 27:377382.

Alves F.R., Feitosa M.L.T., Gatti A., Fadel L., Unruh S.M., Ambrósio C.E., Sterman F.A., Pinto A.C.B.C.F. \& Miglino M.A. 2009. Imagem radiográfica da cavidade torácica de cães Golden Retriever acometidos pela distrofia muscular. Pesq. Vet. Bras. 29:99-104.

Ankel-Simons F. 2000. Primate Anatomy. $2^{\text {nd }}$ ed. Academic Press, London. $724 \mathrm{p}$.

Andriacchi T., Schultz A., Belytschko T. \& Galante J. 1974. A model for studies of mechanical interactions between the human spine and rib cage. J. Biomech. 7:497-507.

Bavegems V., Van Caelenberg A., Duchateau L., Sys S., Van Bree H. \& de Rick A. 2005. Vertebral heart size ranges specific for whippets. Vet. Radiol. Ultras. 46:400-403.

Buchanan J.W. \& Bücheler J. 1995. Vertebral scale system to measure canine heart size in radiographs. J. Am. Vet. Med. Assoc. 206:194-199.

Csatadi K., Leus K. \& Pereboom J.J.M. 2008. A brief note on the effects of novel enrichment on an unwanted behavior of captive bonobos. Appl. Anim. Behav. Sci. 112:201-204.

Cyriax J.H. \& Cyriax P.J. 1993. Illustrated Manual of Orthopaedic Medicine. $2^{\text {nd }}$ ed. Butterworth-Heinemann Medical, Oxford. 268p.

Domingues S.F.S., Caldasbussiere M., Martins N. \& Carvalho R. 2007. Ultrasonographic imaging of the reproductive tract and surgical recovery of oocytes in Cebus apella (capuchin monkeys). Theriogenol. 68:12511259.

Edmondson S.J. \& Singer K.P. 1997. The thoracic spine: Anatomical and biomechanical considerations for manual therapy. Man Ther. 2:132-143.

Edmondston S.J., Singer K.P., Day R.E., Breidahl P.D. \& Prices R.I. 1994. In-vitro relationships between vertebral body density, size and compressive strength in the elderly thoracolumbar spine. Clin. Biomech. 9:180-186.

Evans H.E. \& Christensen G.C. 1993. Miller's Anatomy of the Dog. $3^{\text {rd }}$ ed. W.B. Saunders Company, Philadelphia. 1113p.

Freese C.H. \& Oppenheimer J.R. 1981. The capuchin monkeys, genus $\mathrm{Ce}$ bus, p.331-390. In: Coimbra-Filho A.F. \& Mittermeir R.A. (Eds), Ecology and Behavior of Neotropical Primates. Academia Brasileira de Ciências, Rio de Janeiro.
Hunt K.D., Cant J.G.H., Gebo D.L., Rose M.D., Walker S.E. \& Youlatos D. 1996. Standardized descriptions of primate locomotor and postural modes. Primates 37:363-387.

Kealy J.K., McIlister H. \& Graham J.P. 2011. Thorax, p.221-231. In: Ibid. (Eds), Diagnostic Radiology and Ultrasound of the Dog and Cat. Saunders Elsevier, St Louis.

Lee M.Y., Lee S.H., Lee S.G., Park S.H., Lee C.Y., Kim K.H., Hwang S.H., Lim S.Y., Ahn Y.K. \& Han H.J. 2007. Comparative analysis of heart functions in micropigs and conventional pigs using echocardiography and radiography. J. Vet. Sci. 8:7-14.

Litster A.L. \& Buchanan J.W. 2000. Vertebral scale system to measure heart size in radiographs of cats. J. Am. Vet. Med. Assoc. 216:210-214.

Maï W., O’Brien R., Scrivani P., Porat-Mosenco Y., Tobin E., Seiler G., McConnell F., Schwarz T. \& Zwingenberger A. 2008. The lung parenchyma, p.250-257. In: Schwarz T. \& Johnson V. (Eds), BSAVA Manual of Canine and Feline Thoracic Imaging. Quedgeley, England.

Masharawi Y., Salame K., Mirovsky V., Peleg S., Dar G., Steinberg N. \& Hershkovitz I. 2008. Vertebral body shape variation in the thoracic and lumbar spine: characterization of its asymmetry and wedging. Clin. Anat. 21:46-54.

Medd R.K. 1971. Routine thoracic radiography in health monitoring of small primates. Brit. Vet. J. 127:220-227.

Mittermeir R.A. \& Coimbra-Filho A.F. 1977. Primate conservation in Brazilian Amazonia, p.117-166. In: Rainier \& Bourne (Eds), Primate Conservation. Academic Press, New York.

Morgan J.P., Wind A. \& Davidson A.P. 2000. Transitional lumbosacral vertebrae, p.223-229. In: Morgan, Wind \& Davidson (Eds), Hereditary Bone and Joint Diseases in the Dog. Schlütersche, Hannover.

Nassar-Montoya F., Sainsbury A.W., Kirkwood J.K. \& Du Boulay G.H. 1992. Age determination of common marmosets (Callithrix jacchus) by radiographic examination of skeletal development. J. Med. Primatol. 21:259264.

Nickel R.A., Schummer A. \& Seiferle E. 1981. The Anatomy of the Domestic Animals. Verlag Paul Parey, Berlin. 610p.

Ramirez O.R. \& Thrall D.E. 1998. A review of imaging techniques for canine cauda equina syndrome. Vet. Radiol. Ultras. 39:283-296.

Schillaci M.A., Jones-Engel L., Lee B.H., Fuentes A., Aggimarangsee N., Engel G.A., Gregorya E. \& Tulyawat S. 2007. Morphology and somatometric growth of long-tailed macaques (Macaca fascicularis fascicularis) in Singapore. Biol. J Linn. Soc. 92:675-694.

Schillaci M.A., Jones-Engel L., Heidrich J.E., Benamore R., Pereira A. \& Paul N. 2008. Thoracic radiography of pet macaques in Sulawesi, Indonesia. J. Med. Primatol. 37:141-145.

Silverman S. 1975. Diagnostic radiology: Its utilization in non-human primate medicine. J. Am. Assoc. Lab. Anim. Sci. 25:748-752.

Silverman S. \& Morgan J.P. 1980. Thoracic radiography of the normal rhesus macaque (Macaca mulatta). Am. J. Vet. Res. 41:1704-1719.

Wagner W.M. \& Kirberger R.M. 2005. Radiographic anatomy of the thorax and abdomen of the common marmoset (Callithrix jacchus). Vet. Radiol. Ultras. 46:217-222.

Wirz A., Truppa V. \& Riviello M.C. 2008. Hematological and plasma biochemical values for captive tufted capuchin monkeys (Cebus apella). J. Med. Primatol. 70:463-472. 